\title{
The Whole Truth about Partial Truth Tables
}

\author{
Keith Burgess-Jackson \\ The University of Texas at Arlington, Arlington, TX, USA \\ Email:kbj@uta.edu,kbj4@att.net
}

How to cite this paper: Burgess-Jackson, K. (2020). The Whole Truth about Partial Truth Tables. Open Journal of Philosophy, 10, 192-219.

https://doi.org/10.4236/ojpp.2020.102014

Received: February 28, 2020

Accepted: May 5, 2020

Published: May 8, 2020

Copyright $(\odot) 2020$ by author(s) and Scientific Research Publishing Inc. This work is licensed under the Creative Commons Attribution International License (CC BY 4.0).

http://creativecommons.org/licenses/by/4.0/

\begin{abstract}
Partial truth tables have two salient virtues. First, like whole truth tables, they are algorithmic (i.e., effective). If you construct them correctly, you will get an answer to your question whether a particular argument is valid; whether a particular proposition is tautologous, self-contradictory, or contingent; or whether a particular set of propositions is consistent. Second, they are less time-consuming and tedious to construct than whole truth tables. No partial truth table has more than three rows, and many have only one. A whole truth table, by contrast, may have as many as $32,64,128$, or 256 rows (or more). In this essay, I explain what a partial truth table is and show how such a table is constructed. I then apply the partial-truth-table technique successively to arguments, individual propositions, and sets of two or more propositions. I conclude by evaluating the most widely used logic textbooks, showing what they do well and where they fall short.
\end{abstract}

\section{Keywords}

Truth Tables, Partial Truth Tables, Validity, Invalidity, Consistency, Inconsistency, Tautologousness, Self-Contradictoriness, Contingency

\section{Truth Tables and Their Uses}

algorithm A mechanical method (i.e., one determined by strict rules, needing no creativity or ingenuity to apply) for carrying out a given calculation in a finite number of steps. Also called 'decision procedure' or 'effective procedure' (Martin, 2002: p. 21 [boldface in original]). ${ }^{1}$

Half a century ago, in his Encyclopedia of Philosophy entry entitled "Glossary of Logical Terms," Boruch A. Brody (1967: p. 76) defined "truth table" as follows: "A table that shows the truth-value of a compound proposition for every

${ }^{1}$ I use the term "effective procedure" rather than "algorithm" in the remainder of the essay. 
possible combination of the truth-values of its constituent propositions."2 Brody's entry makes no mention of the use or uses to which a truth table may be put. As it turns out, truth tables are remarkably versatile. There are four main uses:

1) To define logical connectives/operators;

2) To classify propositional forms (hereafter "propositions");

3) To compare propositions; and

4) To test argument forms (hereafter "arguments") for validity.

At the risk of boring a few readers ${ }^{3}$, let me say a few words about each of these uses before proceeding to the main topic of the essay, which is partial truth tables. Eventually, I will show that partial truth tables, no less than full or whole truth tables, may be used to classify and compare propositions and to test arguments for validity (the second, third, and fourth uses).

\subsection{Defining}

Here are the definitions of the five logical connectives/operators:

\begin{tabular}{ccccc}
\hline Negation & Conjunction & Disjunction & Material Implication & Material Equivalence \\
\hline$\sim \mathrm{p}$ & $\mathrm{p} \bullet \mathrm{q}$ & $\mathrm{p} \vee \mathrm{q}$ & $\mathrm{p} \supset \mathrm{q}$ & $\mathrm{p} \equiv \mathrm{q}$ \\
$\mathrm{FT}$ & $\mathrm{T} \mathrm{T} \mathrm{T}$ & T T T & T T T & T T T \\
TF & T F F & T T F & T F F & T F F \\
& F F T & F T T & F T T & F F T \\
& F F F & F F F & F T F & F T F \\
\hline
\end{tabular}

The truth tables may be thought of as defining (or perhaps as facilitating or illustrating the definition of) the various connectives/operators.

\subsection{Classifying}

Every proposition is either a tautology, a self-contradiction, or a contingent proposition, and no proposition is more than one of these. ${ }^{4}$ If the truth table for a proposition has all "T's" under its main connective, then it is a tautology. If it has all "F'," then it is a self-contradiction. If it has at least one "T" and at least one " $\mathrm{F}$," then it is a contingent proposition. Another classification is "self-consistency." If the truth table for a proposition has at least one " $\mathrm{T}$ " under

${ }^{2}$ The author of this entry is Baruch Brody (1943-2018), who taught at Rice University in Houston, Texas. For some reason, his name was spelled "Boruch" both at the end of the encyclopedia entry and in the list of contributors in the first volume.

Here is an alternative definition of "truth table": "A diagram used in sentential logic to display the systematic way the truth or falsity of a truth-functional sentence depends on the truth or falsity of its component sentences" (Martin, 2002: p. 307).

There is some debate about the origins of truth tables. See, e.g., Shosky, 1997; Anellis, 2004; and Anellis, 2012. I take no side in this debate.

${ }^{3}$ I apologize for the quotidian language of this essay. While it is written for my philosophical colleagues who teach logic, it is meant to be read and understood by first-year college students as well. My hope is that instructors will assign the essay to their students at the appropriate point of their courses.

${ }^{4}$ The categories, in other words, are mutually exclusive and jointly exhaustive. 
its main operator, then it is a self-consistent proposition. Suppose you are wondering about the status of the proposition “ $[(p \supset q) \supset p] \supset p$ ”. Here is its truth table:

$\begin{array}{ccccccc}{[(\mathrm{p}} & \supset & \mathrm{q}) & \supset & \mathrm{p}] & \supset & \mathrm{p} \\ \mathrm{T} & \mathrm{T} & \mathrm{T} & \mathrm{T} & \mathrm{T} & \mathrm{T} & \mathrm{T} \\ \mathrm{T} & \mathrm{F} & \mathrm{F} & \mathrm{T} & \mathrm{T} & \mathrm{T} & \mathrm{T} \\ \mathrm{F} & \mathrm{T} & \mathrm{T} & \mathrm{F} & \mathrm{F} & \mathrm{T} & \mathrm{F} \\ \mathrm{F} & \mathrm{T} & \mathrm{F} & \mathrm{F} & \mathrm{F} & \mathrm{T} & \mathrm{F}\end{array}$

The column under the main connective (the third horseshoe from the left) has all "T's" in it, so the proposition-known as Peirce's Law-is both a self-consistent proposition and a tautology. (You will note that " $\mathrm{x}$ is a tautology" is the superaltern of " $\mathrm{x}$ is a self-consistent proposition". See immediately below for the formal definition of "superaltern.")

\subsection{Comparing}

There are nine interesting comparisons (i.e., logical relations) between or among propositions. Here they are, together with their formal definitions (let " $\mathrm{X}$ " and "Y" stand for propositions):

1) Logical implication (a.k.a. entailment). $\mathrm{X}$ logically implies $\mathrm{Y}$ iff it is logically impossible (hereafter "impossible") for $\mathrm{X}$ to be true while $\mathrm{Y}$ is false.

2) Logical equivalence (a.k.a. bidirectional entailment). $\mathrm{X}$ is logically equivalent to $\mathrm{Y}$ (i.e., $\mathrm{X}$ and $\mathrm{Y}$ are logically equivalent [to one another]) iff (1) it is impossible for $\mathrm{X}$ to be true while $\mathrm{Y}$ is false and (2) it is impossible for $\mathrm{Y}$ to be true while $\mathrm{X}$ is false. In other words, $\mathrm{X}$ logically implies $\mathrm{Y}$ and $\mathrm{Y}$ logically implies $\mathrm{X}$.

3) Contradictoriness. $\mathrm{X}$ is the contradictory of $\mathrm{Y}$ (i.e., $\mathrm{X}$ and $\mathrm{Y}$ are contradictories [of one another]) iff (1) it is impossible for both $\mathrm{X}$ and $\mathrm{Y}$ to be true and (2) it is impossible for both $\mathrm{X}$ and $\mathrm{Y}$ to be false.

4) Contrariety. $\mathrm{X}$ is the contrary of $\mathrm{Y}$ (i.e., $\mathrm{X}$ and $\mathrm{Y}$ are contraries [of one another]) iff (1) it is impossible for both $\mathrm{X}$ and $\mathrm{Y}$ to be true and (2) it is logically possible (hereafter "possible") for both $\mathrm{X}$ and $\mathrm{Y}$ to be false.

5) Subcontrariety. $\mathrm{X}$ is the subcontrary of $\mathrm{Y}$ (i.e., $\mathrm{X}$ and $\mathrm{Y}$ are subcontraries [of one another]) iff (1) it is possible for both $\mathrm{X}$ and $\mathrm{Y}$ to be true and (2) it is impossible for both $\mathrm{X}$ and $\mathrm{Y}$ to be false.

6) Subalternation (a.k.a. unidirectional entailment). $\mathrm{X}$ is the superaltern of $\mathrm{Y}$ (or, conversely, $\mathrm{Y}$ is the subaltern of $\mathrm{X}$ ) iff (1) it is impossible for $\mathrm{X}$ to be true while $\mathrm{Y}$ is false and (2) it is possible for $\mathrm{Y}$ to be true while $\mathrm{X}$ is false. In other words, $\mathrm{X}$ logically implies $\mathrm{Y}$ and $\mathrm{Y}$ does not logically imply $\mathrm{X}$.

7) Independence. $\mathrm{X}$ is independent of $\mathrm{Y}$ (i.e., $\mathrm{X}$ and $\mathrm{Y}$ are independent [of one another]) iff (1) it is possible for $\mathrm{X}$ to be true while $\mathrm{Y}$ is false; (2) it is possible for $\mathrm{Y}$ to be true while $\mathrm{X}$ is false; (3) it is possible for both $\mathrm{X}$ and $\mathrm{Y}$ to be true; and (4) it is possible for both $\mathrm{X}$ and $\mathrm{Y}$ to be false.

8) Consistency. $\mathrm{X}$ is consistent with $\mathrm{Y}$ (i.e., $\mathrm{X}$ and $\mathrm{Y}$ are consistent [with one 
another]) iff it is possible for both $\mathrm{X}$ and $\mathrm{Y}$ to be true.

9) Inconsistency. $\mathrm{X}$ is inconsistent with $\mathrm{Y}$ (i.e., $\mathrm{X}$ and $\mathrm{Y}$ are inconsistent [with one another]) iff it is impossible for both $\mathrm{X}$ and $\mathrm{Y}$ to be true.

Truth tables are convenient devices for determining, for any two (or more) propositions, the logical relations in which they stand to one another. Here are the indicators:

1) Logical implication. There is no row of the truth tables for $X$ and $Y$ in which $\mathrm{X}$ is true and $\mathrm{Y}$ false.

2) Logical equivalence. There is no row of the truth tables for $X$ and $Y$ in which $\mathrm{X}$ and $\mathrm{Y}$ have different truth values.

3) Contradictoriness. There is no row of the truth tables for $X$ and $Y$ in which $\mathrm{X}$ and $\mathrm{Y}$ have the same truth value.

4) Contrariety. There is no row of the truth tables for $X$ and $Y$ in which both $X$ and $\mathrm{Y}$ are true, but there is at least one row of the truth tables for $\mathrm{X}$ and $\mathrm{Y}$ in which both $\mathrm{X}$ and $\mathrm{Y}$ are false.

5) Subcontrariety. There is no row of the truth tables for $\mathrm{X}$ and $\mathrm{Y}$ in which both $\mathrm{X}$ and $\mathrm{Y}$ are false, but there is at least one row of the truth tables for $\mathrm{X}$ and $\mathrm{Y}$ in which both $\mathrm{X}$ and $\mathrm{Y}$ are true.

6) Subalternation. There is no row of the truth tables for $\mathrm{X}$ and $\mathrm{Y}$ in which $\mathrm{X}$ is true and $\mathrm{Y}$ false, but there is at least one row of the truth tables for $\mathrm{X}$ and $\mathrm{Y}$ in which $\mathrm{Y}$ is true and $\mathrm{X}$ false.

7) Independence. There is at least one row of the truth tables for $\mathrm{X}$ and $\mathrm{Y}$ in which $\mathrm{X}$ is true and $\mathrm{Y}$ false; there is at least one row of the truth tables for $\mathrm{X}$ and $\mathrm{Y}$ in which $\mathrm{Y}$ is true and $\mathrm{X}$ false; there is at least one row of the truth tables for $\mathrm{X}$ and $\mathrm{Y}$ in which both $\mathrm{X}$ and $\mathrm{Y}$ are true; and there is at least one row of the truth tables for $\mathrm{X}$ and $\mathrm{Y}$ in which both $\mathrm{X}$ and $\mathrm{Y}$ are false.

8) Consistency. There is at least one row of the truth tables for $\mathrm{X}$ and $\mathrm{Y}$ in which both $\mathrm{X}$ and $\mathrm{Y}$ are true.

9) Inconsistency. There is no row of the truth tables for $\mathrm{X}$ and $\mathrm{Y}$ in which both $\mathrm{X}$ and $\mathrm{Y}$ are true.

Suppose you are wondering how the propositions " $\mathrm{p} \equiv \mathrm{q}$ ” and “( $\mathrm{p} \bullet \mathrm{q}) \vee(\sim \mathrm{p} \bullet$ $\sim q)$ " are related to one another. Here are the propositions (separated from one another by a single slash), together with their respective truth tables:

$$
\begin{aligned}
& p \equiv q /(p \bullet q) \vee(\sim p \bullet \sim q)
\end{aligned}
$$

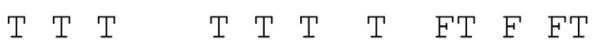

$$
\begin{aligned}
& \begin{array}{lllllllll}
T & F & \mathrm{~T} & \mathrm{~F} & \mathrm{~F} & \mathrm{~F} & \mathrm{FT} & \mathrm{F} & \mathrm{TF}
\end{array}
\end{aligned}
$$

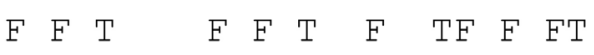

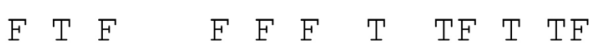

Proceeding through the list of relations, one discovers the following: 1) the first proposition logically implies the second; 2) the second proposition logically implies the first; 3) the propositions are logically equivalent (to one another); and 4 ) the propositions are consistent (with one another). Four of the nine rela- 
tions (three, if we count logical implication only once) are exemplified by this pair of propositions.

\subsection{Testing}

A fourth use of truth tables is to test arguments for validity. Suppose you are wondering whether the following argument is valid: " $p \supset q$ "; "q"; therefore, "p". Here are the three propositions (the premises separated from one another by a single slash and from the conclusion by a double slash), together with their respective truth tables:

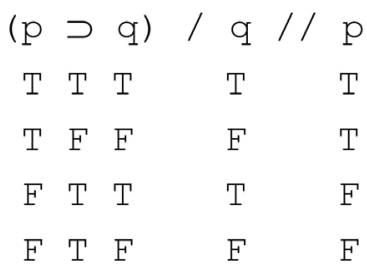

If there is even one row of the truth table in which all the premises are true and the conclusion false, then the argument is invalid. If there is no such row, then the argument is valid. This argument (the Fallacy of Affirming the Consequent) is invalid, as can be seen in the third row.

The purpose of this section (Section 1) has been to review the various uses of truth tables. There may be other uses, but those mentioned are the main ones. At least with respect to its second, third, and fourth uses, a truth table is an effective procedure in that it "results in a solution to a problem in a finite number of steps" (Blackburn, 2008: p. 110). If you construct a truth table correctly, you will get an answer to your question whether a given proposition is, for example, a self-contradiction; whether two propositions are, for example, independent (of one another); and whether a particular argument is valid.

\section{Partial Truth Tables}

Each truth table so far constructed has four rows. This is because each contains two different simple propositions. The formula for determining the number of

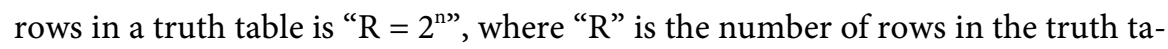
ble and " $\mathrm{n}$ " is the number of different simple propositions. An argument with two different simple propositions (such as Modus Ponens) requires a truth table of four rows; an argument with three different simple propositions (such as Hypothetical Syllogism) requires a truth table of eight rows; an argument with four different simple propositions (such as Constructive Dilemma) requires a truth table of 16 rows; and so on.

The wieldiness ${ }^{5}$ of a truth table is inversely proportional to the number of different simple propositions it contains. Constructing a 32-row, 64-row, 128-row,

5"Wieldy" (adjective), which is a back-formation from "unwieldy," means "easily controlled or handled” (New Oxford American Dictionary, 2010: p. 1976). 
or 256-row truth table can be done, but it will be time-consuming and tedious.

Fortunately for those of us whose time (or patience) is limited, there is a shorter-but no less effective ${ }^{6}$ - procedure known as the partial-truth-table technique. ${ }^{7}$ This technique is discussed in most of the logic textbooks that are now on the market, but the discussions are-as I show in Section 3-either incomplete, unnecessarily complicated, or downright confusing. My aim in this essay is to set out a simple, straightforward, student-friendly partial-truth-table technique.

\subsection{Introduction}

I now present six examples, two of which require a one-row truth table, two of which require a two-row truth table, and two of which require a three-row truth table. In each pair of examples, one argument is valid and the other invalid. Here, in chart form, are the arguments we will be discussing:

\begin{tabular}{lll}
\hline & Valid & Invalid \\
\hline \multirow{2}{*}{ One Row } & $(\mathrm{p} \supset \mathrm{q}) \bullet(\mathrm{r} \supset \mathrm{s})$ & $\mathrm{p} \supset \mathrm{q}$ \\
& $\mathrm{p} \vee \mathrm{r}$ & $\sim \mathrm{p}$ \\
& $\therefore \mathrm{q} \vee \mathrm{s}$ & $\therefore \sim \mathrm{q}$ \\
& $\mathrm{p} \equiv \mathrm{q}$ & \\
Two Rows & $\therefore(\mathrm{p} \supset \mathrm{q}) \bullet(\mathrm{q} \supset \mathrm{p})$ & $\therefore \mathrm{p} \supset \mathrm{q}) \vee(\mathrm{q} \supset \mathrm{p})$ \\
& $(\mathrm{p} \bullet \mathrm{q}) \vee(\mathrm{p} \bullet \mathrm{q})$ & $\mathrm{p} \vee \mathrm{q}$ \\
Three Rows & $\therefore \mathrm{p} \bullet(\mathrm{q} \vee \mathrm{r})$ & $\therefore \mathrm{p} \bullet \mathrm{q}$ \\
\hline
\end{tabular}

\subsection{Determining the Number of Rows}

The first step in using the partial-truth-table technique is to write the argument on a single line, with a slash between premises and a double slash between the final premise and the conclusion. The second step is to assign truth values to the premises and conclusion in such a way as to make the premises true and the conclusion false. I will explain the rationale for this assignment shortly. The third step is to determine how many ways there are for each premise to be true and for the conclusion to be false. Recall that there are, in addition to simple

\footnotetext{
${ }^{6}$ I have no proof that the partial-truth-table technique described in this essay is effective. However, I have yet to find an argument that cannot be proved either valid or invalid using the technique, and I have tested hundreds of arguments (including all 385 arguments contained in the various exercise sections of Baronett, 2019). Based on this, I conjecture that the technique is effective. That is to say, I conjecture that 1) all valid arguments expressible in propositional logic are provably valid using the partial-truth-table technique; and 2) all invalid arguments expressible in propositional logic are provably invalid using the partial-truth-table technique.

${ }^{7}$ Other names for this technique are "shorter truth tables" (Copi, Cohen, \& McMahon, 2011: p. 394), "indirect truth tables" (Hurley, 2012: p. 350; Baronett, 2019: p. 377), "the short-cut method" (Kaminsky \& Kaminsky, 1974: p. 116), "reverse truth tables" (Flage, 1995: p. 224), and "abbreviated truth tables" (Anellis, 2012: p. 90). Goldfarb (2003: p. 49) uses the term "partial truth tables," which seems to me preferable to the others because "part" is the natural contrast with "whole." A given argument may be tested for validity by constructing either a whole truth table or only part of a (whole) truth table.
} 
propositions, five different truth-functional compound propositions. A given premise or conclusion is either 1) a simple proposition, 2) a negation, 3) a conjunction, 4) a disjunction, 5) a material conditional, or 6) a material biconditional. Here is a chart that shows the number of ways a given type of proposition may be true or false:

\begin{tabular}{ccc}
\hline Type of Proposition & Ways to Be True & Ways to Be False \\
\hline Simple & 1 & 1 \\
Negation & 1 & 1 \\
Conjunction & 1 & 3 \\
Disjunction & 3 & 1 \\
Material Conditional & 3 & 1 \\
Material Biconditional & 2 & 2 \\
\hline
\end{tabular}

The number of rows in a partial truth table equals the smallest of the numbers that you discover during this process. There are exceptions to this rule, as we shall see, but in no event will a partial truth table have more than three rows. This means that a partial truth table will be shorter (i.e., have fewer rows) than any whole truth table except one in which the argument in question contains only one simple proposition. ${ }^{8}$

Let us begin with the rule (which gives the result in the vast majority of cases) and come back later to the exception. Suppose the first premise of the argument under consideration can be true in one way, its second premise true in three ways, and its conclusion false in one way; then the truth table will have one row, since one is the smallest of the three numbers $(1,3,1)$. If the sole premise of the argument under consideration can be true in three ways and its conclusion false in three ways, then the truth table will have three rows, since three is the smallest of these two numbers $(3,3)$. Every partial truth table will have either one, two, or three rows.

\subsection{A Valid Argument with a One-Row Truth Table}

Now that the technique has been explained, let us examine some arguments. As we proceed, the explanations will become shorter, for I will not need to repeat what has already been said. The explanations will focus on what is new or different. Here is the first argument, which you will recognize as Constructive Dilemma (one of the eight Implication Rules):

$$
(p \supset q) \bullet(r \supset s) / p \vee r / / q \vee s
$$

The first thing we must do is assign truth values so as to make the argument invalid. By definition, no valid argument has true premises and a false conclusion, so let us assign the truth value " $\mathrm{T}$ " (for "true") to each of the two premises

${ }^{8}$ For example, "p"; therefore, “p $\bullet \mathrm{p}$ ”. 
and the truth value "F" (for "false") to the conclusion. I will write the letters immediately below the main connectives of the propositions, as follows:

$$
\begin{gathered}
(\mathrm{p} \supset \mathrm{q}) \bullet(\mathrm{r} \supset \mathrm{s}) / \mathrm{p} \vee \mathrm{r} / / \mathrm{q} \vee \mathrm{s} \\
\mathrm{T}
\end{gathered}
$$

Note that we are assuming that the argument is invalid. If this assumption forces us into a contradiction in every row of the truth table (however many rows there turn out to be), then the assumption (of invalidity) is false and the argument is valid. If the assumption (of invalidity) does not force us into a contradiction in every row of the truth table, i.e., if there is even one row without a contradiction, then the assumption stands and the argument is invalid.

The second thing we must do is determine how many rows there will be in the truth table, for it may be greater than one. We do this by examining the propositions that make up the argument. The first premise is a conjunction. We are assuming that it is true. There is only one way for a conjunction to be true, and that is when both of its conjuncts are true. The second premise is a disjunction. We are assuming that it is true. There are three ways for a disjunction to be true: when both of its disjuncts are true; when its first disjunct is true and its second disjunct false; and when its second disjunct is true and its first disjunct false. The conclusion is a disjunction. We are assuming that it is false. There is only one way for a disjunction to be false, and that is when both of its disjuncts are false.

To summarize, we have one way to make the first premise true, three ways to make the second premise true, and one way to make the conclusion false. As we saw above, the smallest of these three numbers $(1,3,1)$ determines the number of rows in the truth table. Since one is smaller than three, there will be only one row in the truth table for this argument. Here it is again:

$$
\begin{array}{r}
(p \supset q) \bullet(r \supset s) / p \vee r / / q \vee s \\
T \\
T
\end{array}
$$

We are now in a position to fill in the remaining columns of the truth table, based on the truth values that are already present. In order to remember which truth values were assigned to make the argument invalid, I will put those letters in boldface type. (If you were writing on paper, you might circle or draw a box around those letters.) But which proposition shall we fill in first? There are three possibilities: the first premise, the second premise, and the conclusion. The answer is, the proposition that can be made true (or false) in the fewest ways. In this case, as we saw, the first premise can be made true in one way and the conclusion false in one way. So we should choose either the first premise or the conclusion, but not the second premise, for the second premise can be made true in three ways.

Suppose we start with the first premise, which is a conjunction. The only way for this premise to be true is for both of its conjuncts to be true, so let us put the 
letter " $T$ " under the horseshoes, as follows:

$$
\begin{aligned}
& (\mathrm{p} \supset \mathrm{q}) \bullet(\mathrm{r} \supset \mathrm{s}) / \mathrm{p} \vee \mathrm{r} / / \mathrm{q} \vee \mathrm{s} \\
& \begin{array}{llllll}
T & T & T & T & F
\end{array}
\end{aligned}
$$

There are three ways for a conditional to be true, but since there is only one row in this truth table, we have reached a dead end. We cannot tell whether "p", "q", " $\mathrm{r}$ ", or "s" are true or false. Let us therefore turn to the conclusion, which can be made false in only one way. We may leave the truth values under the horseshoes (since they are dictated by our assignments) or remove them and start over. For purposes of exposition, I will start over. Here is the truth table with the conclusion completed:

$$
\begin{array}{r}
(p \supset q) \bullet(r \supset s) / p \vee r / / q \vee s \\
T \\
T
\end{array}
$$

Since the only way for a disjunction to be false is for each of its disjuncts to be false, we know that " $\mathrm{q}$ " and " $\mathrm{s}$ " are false. Let us transfer those truth values to the first premise, where " $\mathrm{q}$ " and " $\mathrm{s}$ " appear. We get this:

$$
\begin{array}{rrrrr}
(p \supset q) & \bullet & (r \supset s) / p \vee r / / q \vee s \\
F & T & F & T & F
\end{array}
$$

Since the first premise is a true conjunction, both of its conjuncts must be true, so we can write the letter "T" under each horseshoe, as follows:

$$
\begin{aligned}
& (p \supset q) \bullet(r \supset s) / p \vee r / / q \vee s \\
& \begin{array}{llllllll}
T & F & T & T & T & F & F & F
\end{array}
\end{aligned}
$$

Since each material conditional is true, and since no true conditional has a true antecedent and a false consequent, we know that the antecedents of these conditionals_ " $\mathrm{p}$ " and " $\mathrm{r}$ "- are false. Let us fill in those truth values:

$$
\begin{aligned}
& (p \supset q) \bullet(r \supset s) / p \vee r / / q \vee s
\end{aligned}
$$

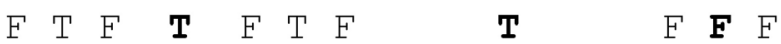

The only remaining task is to fill in the truth values of the second premise, using the truth values for " $\mathrm{p}$ " and " $\mathrm{r}$ " that were just filled in:

$$
\begin{aligned}
& (\mathrm{p} \supset \mathrm{q}) \bullet(r \supset \mathrm{s}) / \mathrm{p} \vee \mathrm{r} / / \mathrm{q} \vee \mathrm{s}
\end{aligned}
$$

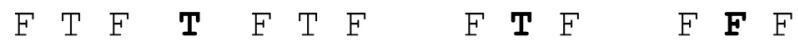

Now that all the columns have been filled in, we are in a position to examine the truth table to see whether we were forced into a contradiction in every row (of which there is just one in this example). Indeed we were: in the second premise. If you were working this exercise on paper or at a blackboard, you might 
wish to circle or draw a box around the truth values under the second premise. I will use underlining:

$$
\begin{array}{lllllllll}
(\mathrm{p} \supset \mathrm{q}) & \bullet & (\mathrm{r} \supset \mathrm{s}) & / \mathrm{p} \vee \mathrm{r} / / \mathrm{q} \vee \mathrm{s} \\
\mathrm{F} \mathrm{T} & \mathrm{F} & \mathrm{F} & \mathrm{T} & \mathrm{F} & \underline{\mathrm{F}} \mathrm{F} & \mathrm{F} & \mathbf{F} & \mathrm{F}
\end{array}
$$

The simple propositions " $p$ " and " $r$ " have been determined to be false, so their disjunction is false; but, as you can see, their disjunction came out true. We have been forced into a contradiction in every row (the only row) of the truth table. The assumption with which we began, therefore, is false. What was that assumption? It was an assumption of invalidity. If it's false that the argument is invalid, then the argument is valid. We knew that, of course, since we knew that Constructive Dilemma is one of the eight Implication Rules. In this case, the partial-truth-table technique simply proves what we already knew. There may be other cases, however, in which we do not know whether the argument is valid. The partial-truth-table technique allows us to ascertain validity (or invalidity) without taking the time to construct a long, unwieldy truth table. (The argument we just considered, which has four different simple propositions, would require 16 rows.)

\subsection{An Invalid Argument with a One-Row Truth Table}

Let us apply the partial-truth-table technique to a second argument:

$$
\mathrm{p} \supset \mathrm{q} / \sim \mathrm{p} / / \sim \mathrm{q}
$$

The first step, as before, is to assign truth values so as to make the argument invalid. This means making the premises true and the conclusion false, as follows:

$$
\underset{\mathbf{T}}{\supset} \underset{\mathbf{T}}{\supset} / \underset{\mathbf{F}}{\sim}
$$

There are three ways to make the first premise true; there is one way to make the second premise true; and there is one way to make the conclusion false. Thus, for the reasons that were given above, we will have a one-row truth table. Where to begin? Since the second premise can be made true in only one way and the conclusion can be made false in only one way, we may begin with either of them. Let us begin with the second premise. Since the negation of " $p$ " is true, "p" itself is false:

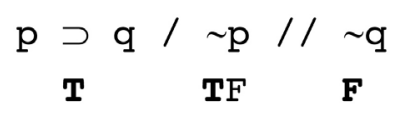

Since the negation of "q" is false, "q" itself is true. Now that we know the truth values of both simple propositions ("p" and "q"), we may complete the truth ta- 
ble:

$$
\begin{array}{lllll}
\mathrm{p} \supset \mathrm{q} / & \sim \mathrm{p} / / & \sim \mathrm{q} \\
\mathrm{F} \mathbf{T} & \mathbf{T F} & \mathbf{F T}
\end{array}
$$

Are there any contradictions? You will see that there are none-so nothing has been circled, enclosed in a box, or underlined. Since we were not forced into a contradiction in every row of the truth table, the assumption with which we began-namely, invalidity-stands. The argument is invalid. You may have known this already, for the argument is a well-known fallacy: Denying the Antecedent.

Let us see what happens when we begin with the conclusion instead of the second premise. Since the negation of "q" is false, "q" itself is true. Transferring the truth value for " $q$ " to the first premise, we get this:

$$
\begin{array}{ccccc}
\mathrm{p} & \supset \mathrm{q} / & \sim \mathrm{p} / / & \sim \mathrm{q} \\
\mathbf{T} \mathrm{T} & \mathbf{T} & \mathbf{F T}
\end{array}
$$

Completing the truth table, we get this:

$$
\begin{array}{lllll}
\mathrm{p} & \supset \mathrm{q} / & \sim \mathrm{p} / / & \sim \mathrm{q} \\
\mathrm{F} & \mathbf{T} & \mathrm{T} F & \mathbf{F T}
\end{array}
$$

The result is the same: no contradictions. What this shows is that sometimes it doesn't matter where we begin. In the first example, you will recall, it did matter where we began.

\subsection{A Valid Argument with a Two-Row Truth Table}

Thus far, we have examined two one-row truth tables. It is time to expand our horizons. Consider the following argument:

$$
p \equiv q / /(p \supset q) \bullet(q \supset p)
$$

As before, let us assume that the premises are true (there is only one premise this time) and the conclusion false. The premise is a biconditional, which can be made true in either of two ways. The conclusion is a conjunction, which can be made false in any of three ways. Since two is smaller than three, we will need a two-row truth table. Here are the two rows with the assigned truth values filled in and put in boldface type:

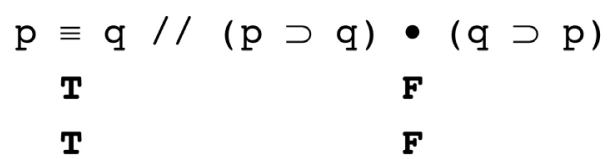

There are two ways for the premise to be true, so fill in the columns under "p" 
and "q" in that premise:

$$
\begin{array}{ll}
\mathrm{p} \equiv \mathrm{q} / /(\mathrm{p} \supset \mathrm{q}) & \bullet(\mathrm{q} \supset \mathrm{p}) \\
\mathrm{T} \mathbf{T} & \mathbf{F} \\
\mathrm{F} \text { T F } & \mathbf{F}
\end{array}
$$

Do not be hasty. Take it row by row, beginning with the first row. Transferring the truth values of " $\mathrm{p}$ " and " $\mathrm{q}$ " in the premise to the other occurrences of "p" and " $q$ " in the first row, we get this:

$$
\begin{array}{lllllllll}
\mathrm{p} & \equiv \mathrm{q} / / & (\mathrm{p} & \supset & \mathrm{q}) & \bullet & (\mathrm{q} & \supset & \mathrm{p}) \\
\mathrm{T} & \mathbf{T} & \mathrm{T} & \mathrm{T} & \mathrm{T} & \mathbf{F} & \mathrm{T} & \mathrm{T} \\
\mathrm{F} & \mathbf{T} & \mathrm{F} & & & \mathbf{F} & &
\end{array}
$$

Now complete the calculation:

$$
\begin{array}{lllllllllll}
\mathrm{p} & \equiv \mathrm{q} / / & (\mathrm{p} & \supset & \mathrm{q}) & \bullet & (\mathrm{q} & \supset & \mathrm{p}) \\
\mathrm{T} & \mathrm{T} & \mathrm{T} & \mathrm{T} & \mathrm{T} & \mathrm{T} & \mathrm{T} & \mathrm{T} & \mathrm{T} \\
\mathrm{F} & \mathrm{T} & \mathrm{F} & & \mathbf{F} & &
\end{array}
$$

We have arrived at a contradiction (in the underlined part of the first row). Both conjuncts of the conclusion are true, so the conjunction itself must be true. But it comes out false according to the calculation. Nothing can be concluded just yet, however. We must complete the second row. If the second row produces a contradiction, then the argument is valid. If it does not produce a contradiction, then the argument is invalid. Completing the second row, we get this:

$$
\begin{aligned}
& \mathrm{p} \equiv \mathrm{q} / /(\mathrm{p} \supset \mathrm{q}) \bullet(\mathrm{q} \supset \mathrm{p})
\end{aligned}
$$

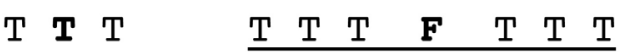

$$
\begin{aligned}
& \begin{array}{lllllllll}
F & T & F & F & F & F & T & F \\
\hline
\end{array}
\end{aligned}
$$

As you can see, there is a contradiction in both rows of the two-row truth table. This proves that the assumption with which we began-namely, invalidity-is false. The argument is valid.

\subsection{An Invalid Argument with a Two-Row Truth Table}

Consider the following argument:

$$
(p \supset q) \vee(q \supset p) / / p \equiv q
$$

The premise, a disjunction, can be made true in three ways. The conclusion, a biconditional, can be made false in two ways. The truth table for this argument will therefore have two rows, since two is smaller than three. Let us assign the truth values in both rows and put the assigned truth values in boldface type: 


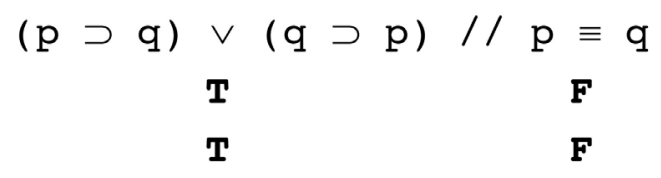

Here are the two ways for the conclusion to be false:

$$
\begin{array}{r}
(p \supset q) \vee(q \supset p) / / p \equiv q \\
T \\
T \\
T
\end{array}
$$

Using the truth values that have been filled in for "p" and " $\mathrm{q}$ ", complete the first row:

$$
\begin{aligned}
& (p \supset q) \vee(q \supset p) / / p \equiv q
\end{aligned}
$$

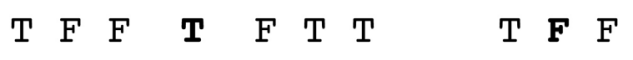

$$
\begin{aligned}
& \text { T F F T }
\end{aligned}
$$

The first row of the partial truth table has been completely and consistently filled in. There is no contradiction. This shows that it is possible for the premise to be true while the conclusion is false. The argument is therefore invalid. There is no need to complete the second row.

\subsection{A Valid Argument with a Three-Row Truth Table}

Some partial truth tables require three rows rather than one or two. (Recall that no partial truth table requires more than three rows.) Consider the following argument:

$$
(p \cdot q) \vee(p \bullet r) / / p \cdot(q \vee r)
$$

The premise, a disjunction, can be made true in three ways. The conclusion, a conjunction, can be made false in three ways. Since the smallest number determines the number of rows in the truth table, the truth table for this argument will require three rows. Let us fill in the truth values for the main operators of the premise and the conclusion, using boldface type:

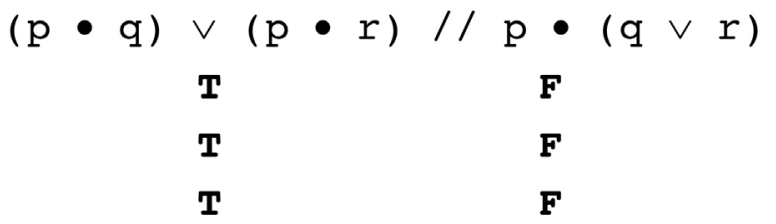

Since there are three ways for the premise to be true and three ways for the conclusion to be false, we may begin with either proposition. Let us arbitrarily select the conclusion. Here are the three ways the conclusion (a conjunction) may be false: 


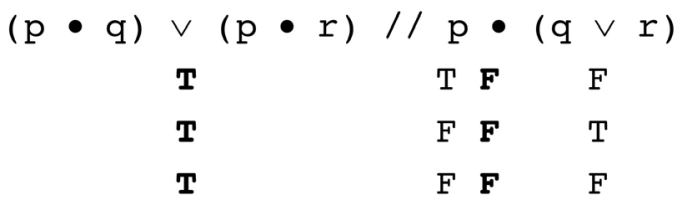

Let us fill in the remainder of the first row:

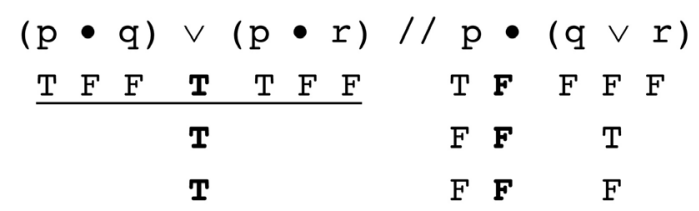

A contradiction appears in the premise. Again, do not be hasty. We must continue to the second row. When we transfer the truth value of " $p$ " to the other two occurrences of "p" and calculate the truth values of the disjuncts of the first premise, we get this:

\begin{tabular}{llllllllllllll}
$(\mathrm{p}$ & $\bullet$ & $\mathrm{q})$ & $\vee$ & $(\mathrm{p}$ & $\bullet$ & $\mathrm{r})$ & $/ /$ & $\mathrm{p}$ & $\bullet$ & $(\mathrm{q}$ & $\vee$ & $\mathrm{r})$ \\
$\mathrm{T}$ & $\mathrm{F}$ & $\mathrm{F}$ & $\mathbf{T}$ & $\mathrm{T}$ & $\mathrm{F}$ & $\mathrm{F}$ & $\mathrm{T}$ & $\mathbf{F}$ & $\mathrm{F}$ & $\mathrm{F}$ & $\mathrm{F}$ \\
$\mathrm{F}$ & $\mathrm{F}$ & $\mathrm{T}$ & $\mathrm{F}$ & $\mathrm{F}$ & & $\mathrm{F}$ & $\mathbf{F}$ & & $\mathrm{T}$ & \\
\hline & & $\mathbf{T}$ & & & $\mathrm{F}$ & $\mathbf{F}$ & & $\mathrm{F}$
\end{tabular}

There is no need to complete the second row, for we have already arrived at a contradiction. We must continue to the third row, which will determine whether the argument is valid. If a contradiction appears there, then the argument is valid. If no contradiction appears there, then the argument is invalid. When we transfer the truth value of "p" to the other two occurrences of "p" and calculate the truth values of the disjuncts of the first premise, we get this:

\begin{tabular}{lllllllllllll}
$(\mathrm{p}$ & $\bullet$ & $\mathrm{q})$ & $\vee$ & $(\mathrm{p}$ & $\bullet$ & $\mathrm{r})$ & $/ /$ & $\mathrm{p}$ & $\bullet$ & $(\mathrm{q}$ & $\vee$ & $\mathrm{r})$ \\
$\mathrm{T}$ & $\mathrm{F}$ & $\mathrm{F}$ & $\mathrm{T}$ & $\mathrm{T}$ & $\mathrm{F}$ & $\mathrm{F}$ & $\mathrm{T}$ & $\mathbf{F}$ & $\mathrm{F}$ & $\mathrm{F}$ & $\mathrm{F}$ \\
$\mathrm{F}$ & $\mathrm{F}$ & $\mathrm{T}$ & $\mathrm{F}$ & $\mathrm{F}$ & $\mathrm{F}$ & $\mathbf{F}$ & $\mathrm{T}$ & \\
\hline $\mathrm{F}$ & $\mathrm{F}$ & $\mathrm{T}$ & $\mathrm{F}$ & $\mathrm{F}$ & & $\mathrm{F}$ & $\mathbf{F}$ & & $\mathrm{F}$
\end{tabular}

We get the same contradiction in the third row that we got in the second row. All three rows of the partial truth table contain a contradiction. This proves that the assumption with which we began-invalidity-is false. The argument is valid.

Before moving on to the next argument, let us see what would have happened had we decided to fill in the columns under the premise rather than under the conclusion. Here is the argument with the main columns filled in:

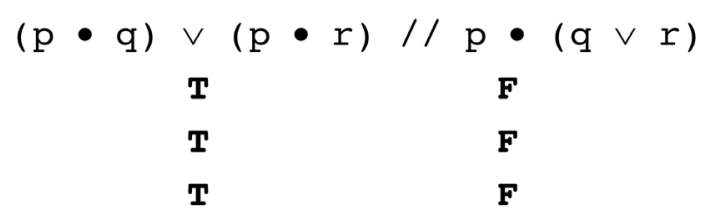


The disjunctive premise can be made true in either of three ways, so let us fill in the columns under the disjuncts:

$$
\begin{array}{ccccc}
(\mathrm{p} \bullet \mathrm{q}) & \vee(\mathrm{p} \bullet \mathrm{r}) / / \mathrm{p} \bullet(\mathrm{q} \vee \mathrm{r}) \\
\mathrm{T} & \mathbf{T} & \mathrm{T} & \mathbf{F} & \\
\mathrm{T} & \mathbf{T} & \mathrm{F} & \mathbf{F} & \\
\mathrm{F} & \mathbf{T} & \mathrm{T} & \mathbf{F}
\end{array}
$$

Let us complete the first row. In order for a conjunction to be true, both of its conjuncts must be true, so we may fill in the truth values for the two conjunctions that serve as disjuncts of the first premise, as follows:

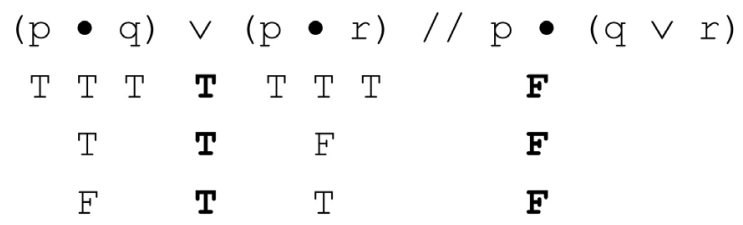

Now complete the first row. We get the following:

$$
\begin{aligned}
& (p \cdot q) \vee(p \bullet r) / / p \bullet(q \vee r) \\
& \mathrm{T} T \mathrm{~T} \quad \mathrm{~T} \quad \mathrm{~T} T \mathrm{~T} \quad \mathrm{~T} \mathbf{F} \mathrm{T} T \mathrm{~T} \\
& \begin{array}{lllll}
T & T & F & F
\end{array} \\
& \begin{array}{lllll}
\text { F } & \text { T } & \text { T } & \text { F }
\end{array}
\end{aligned}
$$

There is a contradiction. Completing the second row, we get this:

$$
\begin{aligned}
& (\mathrm{p} \bullet \mathrm{q}) \vee(\mathrm{p} \bullet \mathrm{r}) / / \mathrm{p} \bullet(\mathrm{q} \vee \mathrm{r}) \\
& \text { T T T T T T T T }
\end{aligned}
$$



$$
\begin{aligned}
& \begin{array}{llll}
F & T & T & F
\end{array}
\end{aligned}
$$

Another contradiction. Completing the third row, we get this:

$$
\begin{aligned}
& (p \bullet q) \vee(p \bullet r) / / p \bullet(q \vee r) \\
& \begin{array}{llllllllllll}
T & T & T & T & T & T & F & T & T
\end{array} \\
& T T T T T F F \text { T } T \text { T T F } \\
& \begin{array}{lllllllllll}
T & F & F & T & T & T & T & F & T & T
\end{array}
\end{aligned}
$$

Yet another contradiction. We have reached the same conclusion as before, namely, that the argument is valid. But notice that the contradictions appear in a different place than they did before, when we started with the conclusion. When we started with the conclusion, we ended up with contradictions in the premise. When we started with the premise, we ended up with contradictions in the conclusion. This shows that it doesn't matter where the contradictions appear, as 
long as they appear.

\subsection{An Invalid Argument with a Three-Row Truth Table}

To this point in our discussion, we have examined three valid arguments: one with a one-row truth table, one with a two-row truth table, and one with a three-row truth table. We have also examined two invalid arguments: one with a one-row truth table and one with a two-row truth table. For the sake of thoroughness, let us examine an invalid argument with a three-row truth table. Here is the argument:

$$
p \vee q / / p \cdot q
$$

You can probably tell, just by examining this argument, that it is invalid; but let us construct the truth table anyway, as an exercise. The disjunctive premise can be made true in three ways and the conjunctive conclusion can be made false in three ways. Therefore, since three is the smallest of these numbers, the truth table will have three rows. Here is the argument with the truth values filled in and put in boldface:

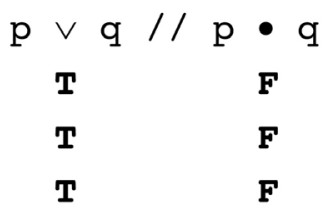

It doesn't matter whether we start with the premise or with the conclusion. I will start with the premise. There are three ways for it to be true:

$\begin{array}{lllll}\mathrm{p} & \vee \mathrm{q} / / \mathrm{p} & \bullet \mathrm{q} \\ \mathrm{T} & \mathbf{T} & \mathrm{T} & \mathbf{F} \\ \mathrm{T} & \mathbf{T} & \mathrm{F} & \mathbf{F} \\ \mathrm{F} & \mathbf{T} & \mathrm{T} & \mathbf{F}\end{array}$

Filling in the remaining columns of the first row, we get this:

$$
\begin{array}{llll}
\mathrm{p} \vee \mathrm{q} / / \mathrm{p} & \bullet \mathrm{q} \\
\mathrm{T} & \mathbf{T} & \mathrm{T} & \mathbf{F} \\
\mathrm{T} & \mathbf{T} & \mathbf{F} \\
\mathrm{F} & \mathbf{T} & \mathrm{T} & \mathbf{F}
\end{array}
$$

There is a contradiction. Completing the second row, we get this:

$$
\begin{array}{llllll}
\mathrm{p} & \vee & \mathrm{q} / / & \mathrm{p} & \bullet \mathrm{q} \\
\mathrm{T} & \mathbf{T} & \mathrm{T} & \mathrm{T} & \mathbf{F} & \mathrm{T} \\
\mathrm{T} & \mathbf{T} & \mathrm{F} & \mathrm{T} & \mathbf{F} & \mathrm{F} \\
\mathrm{F} & \mathbf{T} & \mathrm{T} & & \mathbf{F}
\end{array}
$$


The second row has been completely and consistently filled in, and there is no contradiction. There is no need to complete the third row. The lack of contradiction in the second row proves that it is possible for the premise to be true while the conclusion is false. The assumption of invalidity therefore stands. In order for the assumption to be proved false, there must be a contradiction in every row.

Suppose that we had chosen to start with the conclusion instead of the premise. We would have begun with this:

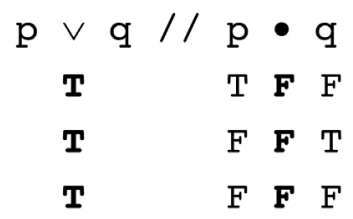

Filling in the remaining columns of the first row, we get this:

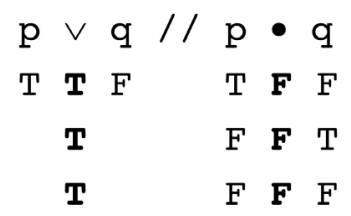

There is no contradiction, which proves, once again, that the argument is invalid. When we started with the premise, it was the second row that was devoid of contradiction. When we started with the conclusion, it was the first row that was devoid of contradiction. What this shows is that it doesn't matter where the lack of contradiction appears. If there is even one row of the partial truth table that is devoid of contradiction, the assumption—of invalidity—stands.

\subsection{The Exception to the Rule}

As mentioned above (in Section 2.2), the rule is that the number of rows in a partial truth table equals the smallest of the numbers that you discover during the analytical phase of the process. Thus far, following that rule has given us the results we seek. But there are exceptions to the rule. Sometimes (though very rarely), the number of rows in the partial truth table must be expanded from the smallest number to a larger number (perhaps to the largest number, which will, however, never be greater than three). Consider the following argument:

$$
\mathrm{p} \supset(\mathrm{q} \supset \mathrm{r}) / \mathrm{q} \supset(\mathrm{p} \supset \mathrm{r}) / /(\mathrm{p} \vee \mathrm{q}) \supset \mathrm{r}
$$

There are three ways to make the first premise true, three ways to make the second premise true, and one way to make the conclusion false. If we apply the rule, therefore, there should be just one row of the partial truth table, as follows:

$$
\begin{aligned}
& \mathrm{p} \supset(\mathrm{q} \supset \mathrm{r}) / \mathrm{q} \supset(\mathrm{p} \supset \mathrm{r}) / /(\mathrm{p} \vee \mathrm{q}) \supset \mathrm{r} \\
& \mathbf{T} \mathbf{T} \quad \mathbf{F}
\end{aligned}
$$


When we fill in as many of the truth values as we can, based on these assignments, we get the following:

$$
\begin{aligned}
& \mathrm{p} \supset(\mathrm{q} \supset \mathrm{r}) / \mathrm{q} \supset(\mathrm{p} \supset \mathrm{r}) / /(\mathrm{p} \vee \mathrm{q}) \supset \mathrm{r} \\
& \begin{array}{llllllll}
\mathbf{T} & \mathrm{F} & \mathbf{T} & \mathrm{F} & \mathrm{T} & \mathbf{F} & \mathrm{F}
\end{array}
\end{aligned}
$$

We are at an impasse. The antecedent of the conclusion ("p $\vee \mathrm{q}$ ") must be assigned the truth value "true" in order for the conclusion to be false (which we are assuming it to be), but the antecedent may be made true in three ways, just as each of the two premises may be made true in three ways. In a case such as this, where the row cannot be completed, we must expand the truth table. Since each of the two premises may be made true in three ways, we may pick either premise for expansion. Let us arbitrarily choose the first premise. Here is the original argument again, with assumptions to make it invalid:

$$
\begin{aligned}
& \mathrm{p} \supset(\mathrm{q} \supset \mathrm{r}) / \mathrm{q} \supset(\mathrm{p} \supset \mathrm{r}) / /(\mathrm{p} \vee \mathrm{q}) \supset \mathrm{r} \\
& \mathbf{T} \mathbf{T} \quad \mathbf{F}
\end{aligned}
$$

The truth table will have three rows, so let us repeat the assigned truth values three times:

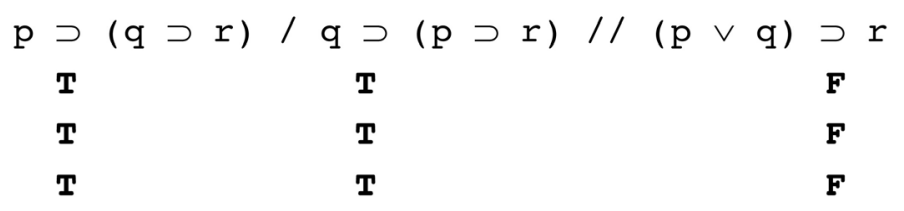

There are three ways for the first premise to be true: where both the antecedent and the consequent are true, where the antecedent is false and the consequent true, and where both the antecedent and the consequent are false. Let us fill in these truth values:

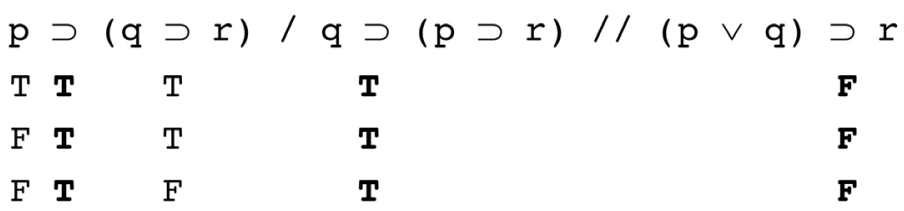

We are now ready to attempt to fill in the first row. If we are forced into a contradiction while doing so, then we will attempt to fill in the second row; and so on. If we complete the first row without being forced into a contradiction, then we will know that the argument is invalid. Transferring the truth value of "p" to the other occurrences of "p", we get this:

$\begin{array}{ccccccccc}\mathrm{p} & \supset & (\mathrm{q} & \supset & \mathrm{r}) & / \mathrm{q} & \supset & (\mathrm{p} \supset \mathrm{r}) / /(\mathrm{p} \vee \mathrm{q}) & \supset \\ \mathrm{T} & \mathbf{T} & \mathrm{T} & \mathrm{T} & \mathrm{T} & & \mathrm{T} & \mathbf{F} \\ \mathrm{F} & \mathbf{T} & \mathrm{T} & \mathrm{T} & & & & \mathbf{F} \\ \mathrm{F} & \mathbf{T} & \mathrm{F} & \mathrm{T} & & & \mathbf{F}\end{array}$


The antecedent of the conclusion is " $(\mathrm{p} \vee \mathrm{q})$ ", and " $\mathrm{p}$ " is true. This makes the disjunction itself true, so let us put a " $T$ " under the wedge:

$\begin{array}{llllllllll}\mathrm{p} & \supset & (\mathrm{q} & \supset \mathrm{r}) & / \mathrm{q} & \supset & (\mathrm{p} \supset \mathrm{r}) & / / & (\mathrm{p} \vee \mathrm{q}) & \supset \mathrm{r} \\ \mathrm{T} & \mathbf{T} & \mathrm{T} & \mathrm{T} & \mathrm{T} & & \mathrm{T} & \mathrm{T} & \mathbf{F} \\ \mathrm{F} & \mathbf{T} & \mathrm{T} & & \mathbf{T} & & & & \mathbf{F} \\ \mathrm{F} & \mathbf{T} & \mathrm{F} & & \mathbf{T} & & & & \end{array}$

We now know that " $\mathrm{r}$ " is false, so let us put an " $\mathrm{F}$ " under all occurrences of "r":

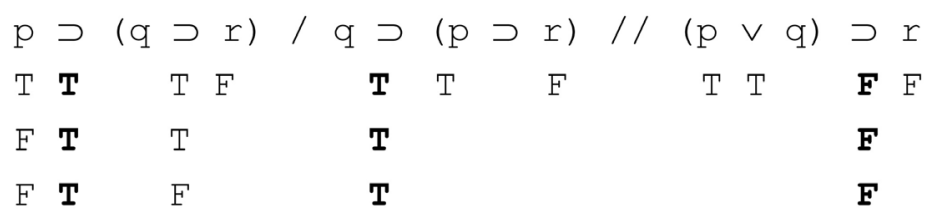

Completing the first row of the truth table, we get this:

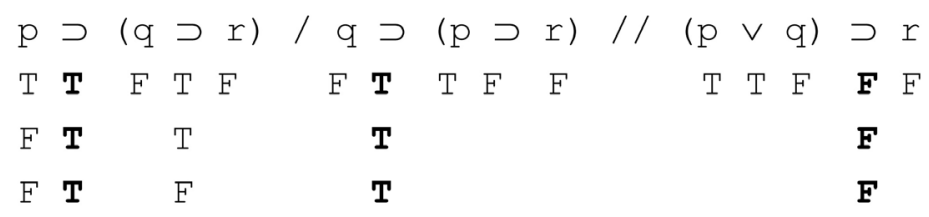

The first row has been completely and consistently filled in, and there is no contradiction. This proves (already, without filling in the second or third rows) that the argument is invalid. By expanding our truth table from one row to three, we arrived at the result we sought. Had we arbitrarily chosen the second premise rather than the first premise for expansion, we would have gotten the same result. Note that a whole truth table for this argument would contain eight rows, which is significantly more than the three it took. ${ }^{9}$

Alas, expansion of the sort we have been discussing is sometimes (very rarely) inconclusive. When this is the case, expansion must occur within a proposition rather than without it. Consider the following argument:

$$
p \vee(q \vee s) / / p
$$

The premise of this argument may be true in three ways and its conclusion false in one way. Following the rule gives this one-row truth table:

$$
\begin{array}{rl}
\mathrm{p} \vee(\mathrm{q} \vee \mathrm{s}) / / \mathrm{p} \\
\mathbf{T} & \mathbf{F}
\end{array}
$$

Completing as much of the truth table as we can, we get this:

\footnotetext{
${ }^{9}$ The following argument would require a truth table of 256 rows, since it contains eight different simple propositions:$$
\mathrm{N} \vee \sim \mathrm{O} / \mathrm{P} \vee \mathrm{O} / \mathrm{P} \supset \mathrm{Q} /(\mathrm{N} \vee \mathrm{Q}) \supset(\mathrm{R} \bullet \mathrm{S}) / \mathrm{S} \supset(\mathrm{R} \supset \mathrm{T}) / \mathrm{O} \supset(\mathrm{T} \supset \mathrm{U}) / / \mathrm{U}
$$

It takes only three rows of an expanded partial truth table to prove its invalidity.
} 


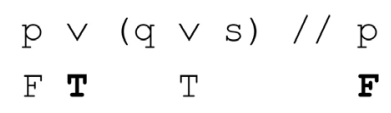

We are at an impasse. The truth values of " $\mathrm{q}$ " and " $\mathrm{s}$ " are undetermined. Let us, therefore, expand the truth table to three rows, since there are three ways for the premise to be true:

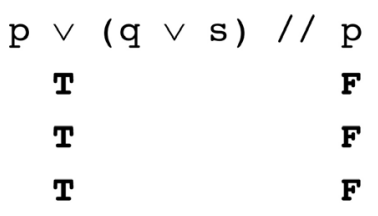

Here are the three ways for the premise to be true:

$\begin{array}{llllll}\mathrm{p} & \vee & (\mathrm{q} \vee & \mathrm{s}) & / / & \mathrm{p} \\ \mathrm{T} & \mathbf{T} & \mathrm{T} & & \mathbf{F} \\ \mathrm{T} & \mathbf{T} & \mathrm{F} & & \mathbf{F} \\ \mathrm{F} & \mathbf{T} & \mathrm{T} & & \mathbf{F}\end{array}$

The first and second rows produce a contradiction, as follows:

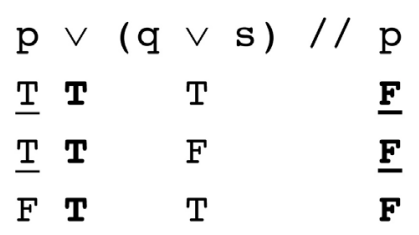

The third row cannot be completed. The truth values of "q" and " $\mathrm{s}$ " remain undetermined. Both following the rule and expanding the truth table have proved inconclusive. What to do?

The answer is that we must expand internally rather than externally. Since the third row is the inconclusive row (note that it was also the inconclusive row of the one-row truth table), let us isolate it:

$$
\begin{aligned}
& p \vee(q \vee s) / / p \\
& \begin{array}{llll}
\mathrm{F} & \mathbf{T} & \mathrm{T} & \mathbf{F}
\end{array}
\end{aligned}
$$

The premise must be assigned the truth value "true," and the conclusion must be assigned the truth value "false". To be consistent, the truth value "false" must be assigned to all occurrences of " $p$ ". This requires that "q $\vee s$ " be true. There are, however, three ways for " $q \vee s$ " to be true. Here they are:

$\begin{array}{lllllll}\mathrm{p} & \vee & (\mathrm{q} & \vee & \mathrm{s}) & / / & \mathrm{p} \\ \mathrm{F} & \mathbf{T} & \mathrm{T} & \mathrm{T} & \mathrm{T} & & \mathbf{F} \\ \mathrm{F} & \mathbf{T} & \mathrm{T} & \mathrm{T} & \mathrm{F} & & \mathbf{F} \\ \mathrm{F} & \mathbf{T} & \mathrm{F} & \mathrm{T} & \mathrm{T} & & \mathbf{F}\end{array}$


We see immediately that the first row of the truth table is filled in completely and consistently, with no contradiction. This proves that the argument is invalid. There is no need to examine the second or third rows. What this example shows is that sometimes (very rarely, actually; see footnote 10) neither following the rule nor expanding the truth table is conclusive. When this is the case, one must expand internally rather than externally. We may, if we wish, refer to these expansions as "internal expansion" and "external expansion."

In light of the fact that it is sometimes necessary to expand the size of the partial truth table (either internally or externally), one might ask: Why not opt (at the outset) for the largest rather than the smallest number discovered during the analytical phase of the process? In the first example discussed in this section (Section 2.9), there were three ways to make the first premise true, three ways to make the second premise true, and one way to make the conclusion false. Why not opt at the outset for three rows rather than one, since we ended up there anyway? The answer is that in the vast majority of cases, the smaller number suffices. That is why it is best to think of $i t$ as the rule. If and when it becomes necessary to expand the number of rows, one may do so, as we did in the previous example. The basis of this preference is nothing more (or less) than efficiency: It's more efficient to have a rule with an occasional exception than to have an exceptionless rule which, more often than not, produces superfluous rows.

To summarize: When using the partial-truth-table technique, follow the rule about using the smallest number of rows, for this, in the vast majority of cases, will produce the result you seek. If you reach an impasse, then you must expand the truth table, either externally or, if that fails, internally. In no event will the expanded truth table exceed three rows. To repeat: follow the rule; if you reach an impasse, then increase the number of rows. Keep going until you get a result: either valid or invalid. ${ }^{10}$

\subsection{Other Uses of Partial Truth Tables}

To this point in the essay, we have used partial truth tables to test the validity of arguments. Partial truth tables may also be used to classify and compare propositions. Let us take these uses in turn, beginning with classification.

Every proposition, as we saw, is either a tautology, a self-contradiction, or a contingent proposition, and no proposition is more than one of these. If I assume that a particular proposition is true (by assigning the truth value "true" to it), then

${ }^{10}$ I mentioned in footnote 6 that I tested all 385 arguments contained in the various exercise sections of Baronett, 2019. Only 16 of the 385 partial truth tables-one of every 24-required expansion. Only four of the 16 that required expansion required internal expansion. See Appendix I for a discussion of these four arguments. Here is a disposition of the 385 arguments:

\begin{tabular}{ccc}
\hline & Arguments (385) (100\%) \\
\hline $\begin{array}{c}\text { Expansion Unnecessary (369) } \\
(95.8 \%)\end{array}$ & Expansion Necessary (16) (4.1\%) \\
& External Expansion Sufficient & Internal Expansion \\
& $(12)(3.1 \%)$ & Necessary and Sufficient (4) \\
\hline
\end{tabular}


either I am forced into a contradiction in every row or I am not. If I am forced into a contradiction in every row, then the proposition is a self-contradiction. If I am not forced into a contradiction in every row, then the proposition is either a tautology or a contingent proposition. To determine which of these is the case, I must make another assumption, this time that the proposition is false. Once again, either I am forced into a contradiction in every row or I am not. If I am forced into a contradiction in every row, then the proposition is a tautology. If I am not forced into a contradiction in every row, then the proposition is a contingent proposition. Here is a flowchart:

$\begin{gathered}\text { Assume that the proposition is true. Does this generate a contradiction in } \\ \text { every row of the partial truth table? }\end{gathered}$
$\begin{gathered}\text { Nos. Then the proposition is either a tautology or a contingent } \\ \text { is a self-contradiction. }\end{gathered}$
$\begin{gathered}\text { proposition. Now assume that the proposition is false. Does this } \\ \text { generate a contradiction in every row of the partial truth table? }\end{gathered}$
$\begin{gathered}\text { Yes. Then the proposition } \\ \text { is a tautology. }\end{gathered} \quad \begin{gathered}\text { No. Then the proposition is a } \\ \text { contingent proposition. }\end{gathered}$

Let us turn from the classification of propositions to comparisons (i.e., logical relations) between propositions, focusing on the relations of consistency and inconsistency. If I assume that two or more propositions are consistent (by assigning the truth value "true" to each of them), then either I am forced into a contradiction in every row or I am not. If I am forced into a contradiction in every row, then the assumption of consistency is false and the propositions are inconsistent. If I am not forced into a contradiction in every row, then the assumption of consistency stands and the propositions are consistent. Consistency and inconsistency are just two of nine logical relations between propositions. See Appendix II for a flowchart that displays all nine relations.

\subsection{Summary of the Use of Partial Truth Tables}

Here is a summary of what we have learned in this essay:

\begin{tabular}{|c|c|c|}
\hline \multirow[b]{2}{*}{ Assumption } & \multicolumn{2}{|c|}{ Outcome } \\
\hline & $\begin{array}{c}\text { Forced into a Contradiction } \\
\text { in Every Row of the Partial } \\
\text { Truth Table }\end{array}$ & $\begin{array}{c}\text { Not Forced into a } \\
\text { Contradiction in Every Row } \\
\text { of the Partial Truth Table }\end{array}$ \\
\hline A Given Proposition Is False & $\begin{array}{l}\text { The Proposition } \\
\text { Is Tautologous }\end{array}$ & $\begin{array}{c}\text { The Proposition Is } \\
\text { Either Self-Contradictory } \\
\text { or Contingent }\end{array}$ \\
\hline A Given Proposition Is True & $\begin{array}{l}\text { The Proposition Is } \\
\text { Self-Contradictory }\end{array}$ & $\begin{array}{l}\text { The Proposition Is Either } \\
\text { Tautologous or Contingent }\end{array}$ \\
\hline $\begin{array}{c}\text { Two or More Propositions } \\
\text { Are Consistent } \\
\text { (with One Another) }\end{array}$ & $\begin{array}{l}\text { The Propositions Are } \\
\text { Inconsistent (with One } \\
\text { Another) }\end{array}$ & $\begin{array}{c}\text { The Propositions Are } \\
\text { Consistent (with One Another) }\end{array}$ \\
\hline $\begin{array}{l}\text { A Given Argument } \\
\text { Is Invalid }\end{array}$ & The Argument Is Valid & The Argument Is Invalid \\
\hline
\end{tabular}


The partial-truth-table technique is an instance (or application) of a more general technique known as reductio ad absurdum (Latin for "reduction to absurdity"), which may be defined as "[t]he process of reasoning that derives a contradiction from some set of assumptions, and concludes that the set as a whole is untenable, so that at least one of [the assumptions] is to be rejected" (Blackburn, 2008: p. 310). The contradiction in this case is the assignment of both truth values ("true" and "false") to the same simple or compound proposition. According to the Law of Noncontradiction, no proposition is both true and false.

\section{Evaluating the Textbooks}

Now that we have described, explained, and illustrated the partial-truth-table technique, we must ask: Do the most widely used logic textbooks mention it? If so, how well do they explain it, and how, if at all, might their treatments of the technique be improved?

\subsection{Copi}

Irving Copi did not mention partial truth tables in the first edition of his classic textbook, Introduction to Logic (Copi, 1953). He did, however, devote two pages to them in the fifth edition of Symbolic Logic (Copi, 1979). (I have examined no editions of this book prior to the fifth.) It was not until the 12th edition of Introduction to Logic (Copi \& Cohen, 2005)—the first to appear after Copi's death on 19 August 2002-that partial truth tables were mentioned, and the treatment there is almost identical to what was said in Symbolic Logic. Partial truth tables continued to be discussed in the 14th edition of 2011, by which time Kenneth McMahon had joined Carl Cohen as author. I have not examined subsequent editions of Introduction to Logic, but I assume that they still include a section on what the authors call the "shorter truth-table technique." In what follows, I use "Copi" and "he" to refer to the authors of all the editions.

Copi's treatment of partial truth tables is not merely abbreviated (it occupies barely more than one page); it is haphazard, in the sense of unsystematic. He explains the technique as follows:

We have seen how an argument may be proved invalid by assigning truth values to its component simple statements in such a way as to make all its premises true and its conclusion false. [Note: This is the method of proving invalidity by assignment.] It is of course impossible to make such assignments if the argument is valid. So we can prove the validity of an argument by showing that no such set of truth values can be assigned. We do this by showing that its premises can be made true, and its conclusion false, only by assigning truth values inconsistently — that is, only with an assignment of values such that some component statement is assigned both a $\mathrm{T}$ and an $\mathrm{F}$. (Copi, Cohen, \& McMahon, 2011: pp. 394-395 [italics and boldface in original]). 
This explanation, which is fine as far as it goes, is followed by one example in which a contradiction is generated in every row of the partial truth table (thus proving validity). There is no indication that the partial-truth-table technique is, even conjecturally, effective. Copi says, rightly, that "This reductio ad absurdum method of assigning truth values is often the quickest method of testing arguments," but then adds: "it is more readily applied in some arguments than in others, depending on the kinds of propositions involved" (Copi, Cohen, \& McMahon, 2011: p. 395). The example given is one in which a disjunction is true or a conjunction false. In that case, Copi says, "we must make various 'trial assignments,' which slows the process and diminishes the advantage of this method" (Copi, Cohen, \& McMahon, 2011: p. 395).

As I have explained, there is an element of "hit-or-miss" when a partial truth table must be expanded. We must sometimes decide which proposition to expand. Perhaps this is what Copi means by "trial assignments." What he does not say is that this is the (rare) exception to the rule rather than the rule itself. Nor does Copi inform his readers that there is a maximum size to a partial truth table. As we have seen, no partial truth table has more than three rows, and the rows can be filled in systematically to see whether a contradiction appears in every row.

Finally, Copi says nothing about other uses of partial truth tables, such as classifying propositions (as tautologus, self-contradictory, or contingent) or comparing propositions (as consistent or inconsistent). Perhaps the present essay will motivate a revision of Copi's treatment of partial truth tables, to 1) make their effective nature clear, 2) discuss when and why expansion is necessary (and explain how to do it), and 3) show how partial truth tables may be used for something other than testing arguments for validity.

\subsection{Hurley}

Patrick Hurley's treatment of partial truth tables (which he calls "indirect truth tables") is far superior to Copi's, and almost as systematic as mine. Hurley begins with an example in which the first premise may be made true in three ways, the second premise true in one way, and the conclusion false in one way. As recommended herein, he constructs a one-row truth table. This leads straightaway to a consistent assignment of truth values, which proves that the argument is invalid.

Hurley's second example has three premises, the first two of which may be made true in three ways and the third of which may be made true in one way. The conclusion may be made false in one way. Again constructing a one-row truth table, he finds a contradiction (in that row), which proves that the argument is valid.

Hurley's third example also has three premises, all of which may be made true in three ways. The conclusion this time may be made false in three ways. This argument, as Hurley correctly points out, requires a truth table of three rows. 
When he fills in the truth values, he gets a contradiction in all three rows, which proves the validity of the argument.

The rule described in the present essay is that the number of rows in the partial truth table equals the smallest number of rows required to make a premise true or the conclusion false. Following this rule almost always suffices to give the answer. Only when it does not give the answer should one expand the truth table. Hurley's rule, by contrast, is as follows:

If an indirect truth table requires more than one line, the method to be followed is this. Either select one of the premises and compute all of the ways it can be made true, or select the conclusion and compute all of the ways it can be made false. This selection should be dictated by the requirement of simplicity. For example, if the conclusion can be made false in only two ways, while each of the premises can be made true in three ways, then select the conclusion. On the other hand, if one of the premises can be made true in only two ways while the conclusion can be made false in three ways, then select that premise. If neither of these situations prevails, then select the conclusion (Hurley, 2012: p. 354).

The only difference between Hurley's treatment and mine is that I begin with a simple rule, namely, choose the smallest number and expand as necessary. Hurley's rule may well produce the same results as mine, but it is not stated as succinctly and may not (therefore) be as easy for students to remember.

Two other shortcomings in Hurley's textbook are worthy of note. First, Hurley fails to give an example in which expansion is necessary, and thus deprives students of advice about what to do in such a situation. One unfortunate result of this omission may be to give students a misleading idea as to the simplicity of the partial-truth-table technique. Sometimes, as we have seen, following the rule leads to an impasse. When that occurs, one must expand the partial truth table, either externally, or, in rare cases, internally. This procedure, as I have explained, is hit-or-miss (though none the less effective). Second, Hurley fails to discuss the use of partial truth tables to classify propositions as tautologous, self-contradictory, or contingent. He does, however, discuss the use of partial truth tables to test propositions (he calls them "statements") for consistency, so he covers two of the three main uses. All in all, Hurley does a good job with partial truth tables. There is, as always, room for improvement.

\subsection{Baronett}

Stan Baronett, a latecomer to the field of textbook writing (the first edition of his book Logic appeared in 2008, whereas Copi's appeared in 1953 and Hurley's in 1982), does an admirable job of explaining certain concepts (such as "truth-functional compound proposition" in the second edition), but his explanation of partial truth tables leaves much to be desired. His presentation of what he calls "indirect truth tables" is not only unsystematic; it is, with all due respect, 
borderline incoherent.

The main problem is that Baronett conflates the method of proving invalidity by assignment (which is not effective) with the partial-truth-table technique (which is effective). Instead of assigning truth values so that the premises of the argument are true and the conclusion false, and then determining whether this generates a contradiction in every row of the partial truth table, he takes a scattershot approach. As he puts it, "the indirect method requires us to look for any possibility of true premises and a false conclusion" (Baronett, 2019: p. 378 [italics omitted]). Actually, it does not require this. It requires us to assume invalidity and then see whether this assumption entails a contradiction in every row.

Perhaps because he conflates the method of proof of invalidity by assignment with the partial-truth-table technique, Baronett fails to see that the latter, unlike the former, is effective. This leads him to say (Baronett, 2019: p. 380) that "The full truth table method is more mechanical in nature" than the partial method. This is, at best, misleading, and at worst mistaken. The property of being mechanical (algorithmic) is all or nothing, not a matter of degree. Both of the truth-table techniques-full and partial-are mechanical, in the sense of effective. It is not clear what it could mean for one method to be more mechanical than another.

To show the sort of problem that the absence of system produces, consider the following. In one of his examples (discussed on pages 379-80), Baronett constructs two rows of a partial truth table when only one row is necessary to prove invalidity. ${ }^{11}$ He also (like Hurley) fails to discuss the use of partial truth tables to classify propositions as tautologous, self-contradictory, or contingent. I recommend that Baronett's section on partial truth tables be reconceived and rewritten (from scratch). In its current form, it is convoluted, confusing, and, as a result, unacceptable. It is by far the worst of the three treatments discussed in this section (Section 3), with Hurley's being substantially the best. Perhaps the present essay will be of some service to Baronett in the revision of his otherwise fine textbook.

\section{Conclusion}

The partial-truth-table technique described in this essay has two salient virtues. Relative to whole truth tables, it is less time-consuming and less tedious, the more so as the number of different simple propositions increases. Relative to $d i$ rect proof, indirect proof, conditional proof, and proof of invalidity by assignment, it is effective. ${ }^{12}$ If you apply the technique as described, you will get an answer-either "Yes" or "No"- to the question, "Is this argument valid?" The technique is also effective in classifying and comparing propositions. If you want to know whether a particular proposition is tautologous, self-contradictory, or contingent (it has to be one of the three, and cannot be more than one), you will

\footnotetext{
${ }^{11}$ The argument is “ $\sim P \bullet R$ "; " $P \vee \sim Q$ ”; therefore, “Q".

${ }^{12}$ Recall from footnote 6 that this is only a conjecture, though one for which there is ample support.
} 
get an answer. If you want to know whether two or more propositions are consistent, you will get an answer.

You now have the whole truth-or as much of it as I can squeeze into one essay-about partial truth tables.

\section{Acknowledgements}

This essay is dedicated to my students: past, present, and future.

\section{Conflicts of Interest}

The author declares no conflicts of interest regarding the publication of this paper.

\section{References}

Anellis, I. (2004). The Genesis of the Truth-Table Device. Russell, 24, 55-70. https://doi.org/10.15173/russell.v24i1.2056

Anellis, I. H. (2012). Peirce's Truth-Functional Analysis and the Origin of the Truth Table. History and Philosophy of Logic, 33, 87-97. https://doi.org/10.1080/01445340.2011.621702

Baronett, S. (2019). Logic (4th ed.). New York: Oxford University Press.

Blackburn, S. (2008). The Oxford Dictionary of Philosophy (2nd ed.). New York: Oxford University Press.

Brody, B. A. (1967). Logical Terms, Glossary of. In P. Edwards (Ed.), The Encyclopedia of Philosophy(Vol. 5, pp. 57-77). New York: Macmillan Publishing Company.

Copi, I. M. (1953). Introduction to Logic. New York: The Macmillan Company.

Copi, I. M. (1979). Symbolic Logic (5th ed.). New York: Macmillan Publishing Company.

Copi, I. M., \& Cohen, C. (2005). Introduction to Logic (12th ed.). Upper Saddle River, NJ: Pearson Prentice Hall.

Copi, I. M., Cohen, C., \& McMahon, K. (2011). Introduction to Logic (14th ed.). Upper Saddle River, NJ: Prentice Hall.

Flage, D. E. (1995). Understanding Logic. Englewood Cliffs, NJ: Prentice Hall.

Goldfarb, W. (2003). Deductive Logic. Indianapolis, IN: Hackett Publishing Company.

Hurley, P. J. (2012). A Concise Introduction to Logic (11th ed.). Boston, MA: Wadsworth.

Kaminsky, J., \& Kaminsky, A. (1974). Logic: A Philosophical Introduction. Reading, MA: Addison-Wesley Publishing Company.

Martin, R. M. (2002). The Philosopher's Dictionary (3rd ed.). Peterborough, Ontario: Broadview Press.

New Oxford American Dictionary (2010). (3rd ed.). New York: Oxford University Press.

Shosky, J. (1997). Russell's Use of Truth Tables. Russell, 17, 11-26. https://doi.org/10.15173/russell.v17i1.1912 


\section{Appendix I}

Only four of the 385 arguments that I tested require internal expansion. Here they are:

$$
\begin{aligned}
& \text { 1. } \mathrm{p} \vee(\mathrm{q} \vee \mathrm{s}) / / \mathrm{p} \\
& \text { 2. }(\mathrm{r} \bullet \mathrm{s}) \supset \mathrm{s} / / \mathrm{s} \\
& \text { 3. } / / \sim[(\mathrm{s} \supset \sim \mathrm{s}) \bullet(\sim \mathrm{s} \supset \mathrm{s})] \\
& \text { 4. } \mathrm{c} \supset\{[\mathrm{d} \supset(\mathrm{e} \supset \mathrm{d})] \supset(\mathrm{f} \bullet \sim \mathrm{f})\} / \mathrm{a} \supset[(\mathrm{b} \supset \mathrm{b}) \supset \mathrm{c}] / / \sim \mathrm{a}
\end{aligned}
$$

The first and second of these arguments are invalid, the third and fourth valid. The first argument (from Baronett, 2019: p. 370) was discussed in the text. In the second argument (also from Baronett, 2019: p. 370), following the rule proves inconclusive. External expansion of the (sole) premise proves inconclusive. Internal expansion of the premise-specifically, proposition " $r$ "-proves conclusive. In the third argument (from Baronett, 2019: p. 470), following the rule proves inconclusive. External expansion is impossible, since there is no premise. Internal expansion of the conclusion-specifically, proposition "s $\supset \sim s$ " - proves conclusive. In the fourth argument (from Baronett, 2019: p. 466), following the rule proves inconclusive. External expansion of the second premise proves inconclusive. External expansion of the first premise proves inconclusive. Internal expansion of the second premise proves inconclusive. Internal expansion of the first premise-specifically, its consequent-proves conclusive.

\section{Appendix II}

Let $\mathrm{X}$ and $\mathrm{Y}$ be propositions:

Assume that $\mathrm{X}$ and $\mathrm{Y}$ are true; are you forced into a contradiction in every row of the partial truth table?

Yes. Then $\mathrm{X}$ is inconsistent with $\mathrm{Y}$. Now assume that $\mathrm{X}$ and $\mathrm{Y}$ are false; are you forced into a contradiction in every row of the partial truth table?

Yes. Then $\mathrm{X}$ is the contradictory No. Then $\mathrm{X}$ is the contrary of Y.

No. Then $\mathrm{X}$ is consistent with $\mathrm{Y}$. Now assume that $\mathrm{X}$ and $\mathrm{Y}$ are false; are you forced into a contradiction in every row of the partial truth table?

Yes. Then $\mathrm{X}$ is $\quad$ No. Now assume that $\mathrm{X}$ is true and $\mathrm{Y}$ false; are you forced into a contradiction in the subcontrary every row of the partial truth table? of $\mathrm{Y}$.

Yes. Then X logically implies Y. Now assume that $\mathrm{Y}$ is true and $\mathrm{X}$ false; are you forced into a contradiction in every row of the partial truth table?

Yes. Then Y No. Then Y does logically implies not logically $\mathrm{X}$. $\mathrm{X}$, therefore, is logically equivalent to $\mathrm{Y}$. imply X. X, therefore, is the superaltern of $\mathrm{Y}$.
No. Then X does not logically imply Y. Now assume that $\mathrm{Y}$ is true and $\mathrm{X}$ false; are you forced into a contradiction in every row of the partial truth table?

Yes. Then Y logically implies $\mathrm{X}$. Y, therefore, is the superaltern of X.
No. Then Y does not logically imply X. X, therefore, is independent of Y. 